\title{
COVID-19: Una mirada desde el Derecho Constitucional
}

COVID-19: A look from Constitutional Law

\author{
Matías Busso ${ }^{1}$ \\ Universidad de Buenos Aires - Argentina
}

Revista Derechos en Acción ISSN 2525-1678/ e-ISSN 2525-1686

Año 5/No 17 Primavera 2020 (21 septiembre a 20 diciembre), 607-625

DOI: https://doi.org/10.24215/25251678e470

Recibido: 01/09/2020

Aprobado: 15/11/2020

Resumen: El trabajo aborda la pandemia del coronavirus desde una mirada constitucional. Propone analizar la problemática que generó el Covid-19, sosteniendo que centrar la cuestión únicamente sobre el virus y su vacuna omitiría la visión biológica total, ocultando la fuente de producción del virus, que seguirá fabricando otros con la misma velocidad que se destruye el ecosistema, causando nuevas infecciones y muertes. Para combatir los virus surgen nuevas "técnicas" y nuevas vacunas, que son producidas con aportes de investigación pública, y son aprovechados por corporaciones transnacionales que las perfeccionan y patentan, limitando su difusión en los países empobrecidos.

Palabras clave: Covid-19, Constitución, pachamama, Zaffaroni.

Abstract: This paper addresses the coronavirus pandemic from a constitutional perspective. He proposes to analyze the problems generated by Covid-19, arguing that focusing the question only on the virus and

\footnotetext{
1 Abogado, Becario Doctoral de CONICET, Docente en la Universidad de Buenos Aires de las materias Teoría General del Derecho y Aspectos Jurídicos de la Violencia Institucional; y en la Universidad de José C Paz de las materias Introducción al Derecho y Función Social de la Administración Democrática de Justicia. (ORCID: https://orcid.org/0000-0001-5632-9129).
} 
its vaccine would omit the total biological vision, hiding the source of production of the virus, which will continue to manufacture others with the same speed that the ecosystem is destroyed, causing new infections and deaths. To combat viruses, new "techniques" and new vaccines are emerging, which are produced with contributions from public research, and are used by transnational corporations that perfect and patent them, limiting their diffusion in impoverished countries.

Keywords: Covid-19, Constitution, Pachamama, Zaffaroni.

\section{Introducción}

El COVID19 nos puso en pausa, nos obligó a pensar y (re) pensar cómo vivimos, en qué lugares, de qué forma, cómo nos alimentamos, que consumimos y hasta cómo respiramos. Nuestro modelo civilizatorio parece estar en jaque "Muchas cosas tienen que reorientar su rumbo, pero ante todo la bumanidad necesita cambiar. Hace falta la conciencia de un origen común, de una pertenencia mutua y de un futuro compartido por todos. Esta conciencia básica permitiría el desarrollo de nuevas convicciones, actitudes y formas de vida." (Laudato Si 202).

En un texto reciente titulado "Perspectiva del poder punitivo post pandemia” el Dr. Eugenio Zaffaroni describe la relación intrínseca entre los sistemas de producción y las infecciones. Allí narra cómo los europeos casi extinguieron la población originaria americana, infectándola con enfermedades zoonóticas $^{2}$, para las que los originarios carecían de anticuerpos, por falta de contacto con los animales que los colonizadores habían domesticado y que en nuestro continente no existían. Luego para compensar la carencia de mano de obra, los colonizadores esclavizaron a africanos, que trajeron la fiebre amarilla ${ }^{3}$. Más

\footnotetext{
2 Una enfermedad zoonótica es una enfermedad que puede transmitirse entre animales y seres humanos. Las enfermedades zoonóticas pueden ser provocadas por virus, bacterias, parásitos y hongos.

3 La fiebre amarilla ha sido causa de epidemias devastadoras en el pasado. Probablemente fue transmitida por primera vez a los humanos por otros primates en África oriental o central.
} 
tarde, resultado de la imposición de dieta cárnica se conoció la triquinosis ${ }^{4}$ y la brucelosis ${ }^{5}$. Por otro lado, marca como la guerra es un desastre ecológico en sí, y como la primera guerra mundial (1914-1918) provocó la llamada gripe española, cuyo nombre no proviene no porque haya tenido ese origen, sino porque los beligerantes ocultaron la información que España difundió. A fines del siglo apareció la vaca loca, por alimentar rumiantes con harina de cadáveres, y también la gripe asiática, la de Hong Kong y el VIH; ya en este siglo la gripe porcina, el SARS, el Ébola y el coronavirus de 2015 y ahora la nueva versión 19.

El autor advierte que estamos produciendo virus en serie: "la brutal depredación planetaria rompe los delicados equilibrios ecológicos creados a lo largo de millones de años, con la torpeza de un mamut en una cristalería. Animales no bumanos pierden su hábitat, se extinguen especies y otras buscan nuevos hogares para sobrevivir, a otras se les crean hábitats artificiales, se les provee alimentación diferente, el estrés activa la antes considerada basura celular, que sufren adaptaciones

De allí se propagó a África occidental y en los siglos XVI o XVII saltó a América debido al tráfico de esclavos. Como la enfermedad era endémica en África, las poblaciones de ese continente habían desarrollado cierta inmunidad a ella y solo les provocaban síntomas similares a los de la gripe. Por el contrario, cuando la epidemia golpeaba a colonos europeos en África o en América la mayoría moría

4 La triquinosis es un tipo de infección provocada por ascáride. Los parásitos ascáride usan un cuerpo huésped para vivir y reproducirse. La infección ocurre principalmente entre animales que comen carne (carnívoros), como osos y zorros, o animales que comen plantas y carne (omnívoros), como cerdos domésticos y jabalíes. La infección se adquiere al comer larvas de ascáride en carne cruda o poco cocida. Cuando los seres humanos comen carne poco cocida que contiene larvas de triquinas, las larvas maduran a gusanos adultos en el intestino en una cuestión de semanas. Los gusanos adultos luego producen larvas que viajan a través de distintos tejidos, incluidos los músculos. La mayoría de las veces, la triquinosis se extiende en zonas rurales por todo el mundo.

5 La brucelosis es una infección bacteriana que se transmite de los animales a las personas. Lo más común es que las personas se infectan al comer productos lácteos crudos o sin pasteurizar. Algunas veces, las bacterias que causan la brucelosis se propagan por el aire o por el contacto directo con animales infectados. 
corporales y de los ensayos y tanteos de la biología en procura de nuevos equilibrios surgen nuevas enfermedades zoonóticas. ${ }^{16}$

El interrogante que nos planteamos es sí así como la formalización de los Derechos Humanos surgió del terror impartido por los genocidios, esta situación crítica de pandemia global puede conducirnos al surgimiento de nuevos derechos y sujetos de derechos. Puede el constitucionalismo abrir nuevos caminos, buscando respuestas en la ecología o el ambientalismo. La educación ambiental que (según el Papa Francisco) estaba centrada en la información científica, en la concientización y prevención de riesgos ambientales, ahora debe incluir una crítica de los "mitos" de la modernidad basados en la razón instrumental (individualismo, progreso indefinido, competencia, consumismo, mercado sin reglas) (LS 210) "Una ruptura radical (como propone Michael Löwy) con la ideología del progreso lineal y con el paradigma tecnológico y económico de la civilización industrial moderna"

¿Pero puede esta crisis ser lo suficientemente profunda como para cuestionar el sistema que nos rige desde hace siglos? ¿Podremos encontrar en el derecho herramientas jurídicas locales y globales que den respuestas a nuestra crisis civilizatoria?

\section{La Pachamama y el Humano}

En su libro la Pachamama y el Humano, Eugenio Zaffaroni plantea el debate respecto a si somos los humanos unos convidados más a participar de la naturaleza o si ésta se creó para nuestro hábitat y tenemos derecho a disponer de ella, siendo sus propietarios o administradores. El humano mantiene una relación ambivalente con su propia animalidad, queriendo ser Dios, pero no pudiendo negar, aunque la reprima, su condición animal. ${ }^{8}$

\footnotetext{
6 ZAFFARONI, Eugenio, "Perspectiva del poder punitivo postpandemia", p 1.

7 Löwy, Michael, Ecologia e Socialismo, San Pablo,Cortez Editora, 2005, p. 43.

8 Zaffaroni, Raul Eugenio; La Pachamama y el Humano;1a ed. Colihue; Ciudad Autónoma de Buenos Aires : Ediciones Madres de Plaza de Mayo, 2011, p 23/24
} 
El platonismo planteo la separación tajante entre cuerpo y alma y el desprecio al cuerpo prepararon el capitalismo. ${ }^{9} \mathrm{Al}$ mismo tiempo relegaron al animal a la condición de puro cuerpo y al humano atento al cuerpo a una condición cercana al animal. El humano no debía preocuparse por el sufrimiento en la tierra, porque su destino estaba en su alma que iría al paraíso" 10

René Descartes, consideró que los animales eran máquinas, desposeídas de toda alma y para el planteamiento cartesiano: los animales son cosas, no existe ninguna obligación a su respecto, son apropiables, objetos del dominio humano, no les asiste ningún derecho ni ninguna limitación ética ni jurídica. El hombre para este pensamiento es señor absoluto de la naturaleza no humana y su misión progresista y racional consiste en dominarla. Por su parte, los criminales, los herejes, las mujeres y los colonizados, eran vistos como humanos inferiores o medio animales. Por ende el poder punitivo, hizo de ellos sus chivos expiatorios, como medio humanos, su parte animal habilitaba su sacrificio, mediante el maltrato, dominación o incluso exterminio.

Esto habilitó la esclavitud de pobladores de África y la colonización o el despojo de los originarios de nuestro continente. Debemos destacar el rol de Bartolomé de las Casas, "procurador y protector universal de todos los yndios de las Yndias", fundador continental de los derechos en las Américas y del empleo, específico y concreto, del concepto "derechos humanos" dos siglos y medio antes (en 1552) que los constituyentes franceses de 1789. ${ }^{11}$

“Con qué derecho y con qué justicia tenéis en tan cruel $y$ horrible servidumbre aquestos indios? ¿Con qué autoridad habéis becho tan detestables guerras a estas gentes que estaban

9 Cfr. León Rozitchner, La cosa y la cruz. Cristianismo y capitalismo (En torno a las “Confesiones" de San Agustín), Buenos Aires, 1997

10 Zaffaroni, Raul Eugenio; La Pachamama y el Humano;1a ed. Colihue; Ciudad Autónoma de Buenos Aires : Ediciones Madres de Plaza de Mayo, 2011, p 23.

11 FILIPPI, Alberto, Constituciones, dictaduras y democracias Los derechos y su configuración política, Infojus, Ciudad Autonoma de Buenos Aires, 2015; p 33 
en sus tierras mansas y pacíficas, donde tan infinitas dellas, con muertes y estragos nunca oídos, habéis consumido? ¿Cómo los tenéis tan opresos y fatigados, sin dalles de comer ni curallos en sus enfermedades, que de los excesivos trabajos que les dais incurren y se os mueren, y por mejor decir, los matáis, por sacar y adquirir oro cada dia? ¿Y qué cuidado tenéis de quien los doctrine, y conozcan a su Dios y criador, sean bautizados, oigan misa, guarden las fiestas y domingos? ¿Estos, no son hombres? ¿No tienen ánimas racionales?"12

En la cultura judeo-cristiana occidental el momento de inflexión de lo humano con lo animal está narrado en el Génesis, cuando Adan y Eva, comiendo la manzana del conocimiento del bien y del mal quisieron ser Dioses, y en ese acto fueron expulsados del Eden, el paraíso o reino animal. Friedrich Nietzsche en "Sobre verdad y mentira en sentido extramoral" dice: "En algún rincón alejado del universo centelleante, perdido entre incontables sistemas solares, bubo una vez un astro en el que animales inteligentes inventaron el conocimiento. Ese fue el minuto más soberbio y falaz de la historia universal".

Zaffaroni en el texto citado describe una continuidad entre humanismo - razón - exclusividad - dominación. Por su parte Foucault en "La verdad y las formas jurídicas" explica como en el siglo XIII el inquisitio, interrogatorio violento, reemplazó el establecimiento de la verdad por lucha y lejos de entrenarnos

12 FILIPPI HISTORIA "Ego vox clamantis in deserto". Sermón pronunciado por fray Antonio de Montesino el cuarto domingo de adviento de 1511 y firmado por todos los miembros de su orden ahora en Historia de las Indias de Bartolomé de las Casas, Tomo II, Libro Tercero, Cap. IV (el destacado es mío). Sobre Pedro de Córdoba, Bernardo de Santo Domingo y Antonio Montesino, los primeros frailes dominicanos en la "isla Española" y la "Tierra Firme" venezolana, "situada en mar de las Indias para fundar conventos y predicar la palabra de Dios", remito al esclarecedor ensayo que los valoriza definitivamente de Luisa Campos Villalón, Pedro de Córdoba, precursor de una comunidad defensora de la vida, Ediciones los libros del amigo, Santo Domingo, 2008 y al trabajo precursor de Juan Manuel Pérez, Estos, ¿no son hombres?. Fundación García Arévalo, Santo Domingo, 1984 así como el ensayo introductorio de Miguel A. Medina, Doctrina cristiana para instrucción de los indios. Redactada por Fr. Pedro de Córdoba, O.P. y otros religiosos doctos de la misma orden. (México 1544-1548), Editorial San Esteban, Salamanca 1987. 
para el diálogo, nos llevó a atrofiar la capacidad de conocer sólo para someter. ${ }^{13}$ En ese sentido todo conocimiento es para subyugar, la relación del sujeto del conocimiento con el objeto de ese conocimiento es siempre de dominación: el primero se sitúa en un plano superior al segundo para interrogarlo, utilizando incluso la violencia, para obtener la respuesta que permita dominarlo. Es una suerte de dominus torturador donde el objeto de conocimiento no tiene derechos ni reglas éticas que respetar. Está habilitada la experimentación, la disección, sin ahorrar sufrimiento ni dolor del objeto a conocer.

No es fácil para el humano escapar al narcisismo que lo conduce a la sujeción del dominus, la reconstrucción de la realidad sobre la base del mismo plano. Si ni siquiera ha logrado el total reconocimiento entre los mismos humanos, ya que a pesar de la existencia de declaraciones y tratados de derechos, el colonialismo, racismo, machismo y xenofobia dominan nuestras relaciones. ¿cuánto le costará reconocer las reglas éticas de las otras especies y de la tierra misma?

La razón como exclusiva capacidad humana, fue sinónimo de dominio, Hegel fue sin duda el ideólogo más fino y sofisticado del colonialismo (entendiendo por colonialismo el dominio centronórdico europeo del planeta). Para este filósofo el Geist, el espíritu, lejos de estar en todo, es un impulso que avanza sólo en la humanidad y lo lleva adelante una parte de ella. En su imparable progreso el fantasmagórico y criminal Geist hegeliano no sólo mató a millones de personas, sino que también fue dejando a su vera a todas las culturas que sometió (por supuesto nuestra América es muestra de ello). ${ }^{14}$

Esa idea de progreso desembocó en la interpretación de la evolución darwiniana de Spencer, donde lo que imperaba era

13 Focuoult, Michel, "La Verdad y las Formas Jurídicas", en el discurso jurídico, en términos de Michel Foucault; http://www.pensamientopenal.com.ar/system/files/2015/01/doctrina40496.pdf, p. 5 (consultado el 28 de Julio de 2020)

14 G. W. F. Hegel, Lecciones sobre la filosofía de la historia universal, trad. de José Gaos, Alianza, Madrid, 1980, pág. 169. 
la competencia y sobreviva el más fuerte. Contra esa idea James Lovelock postula su hipótesis Gaia (diosa griega de la Tierra): según ella el planeta es un ente viviente, no en el sentido de un organismo o animal, sino en el de un sistema que se autorregula. ${ }^{15}$ Se trata de no privilegiar en la evolución la competencia, sino la cooperación: la vida no aparece sobre el planeta sino en forma microscópica, como resultado también de síntesis y complejizaciones moleculares, se simbiotizan, cooperan para sobrevivir y derivan en otro más complejo. Somos el producto de millones de años de complejización simbiótica y no de la lucha sangrienta en la cual sobrevive el más cruel y despiadado. ${ }^{16}$

Debemos pensar que si incluso nuestro cerebro está formado por bacterias simbiotizadas a lo largo de millones de años y somos una pequeña parte de una biosfera bacteriana ${ }^{17}$ El reconocimiento de la simbiosis como fuerza evolutiva tiene implicaciones filosóficas profundas. Todos los organismos macroscópicos, incluidos nosotros, somos prueba viviente de que las prácticas destructivas a la larga fallan. Al final los agresores se destruyen a sí mismos, dejando el puesto a otros individuos que saben cómo cooperar. ${ }^{18}$

La tesis de Lovelock nos dice que si perturbamos demasiado el equilibrio planetario, Gaia decidirá toser o estornudar y prescindir de nosotros para permitir a la vida recomponerse en otros seres complejos menos incómodos o más cooperadores. La ética de la Gaia implica reconocer el derecho de entes no humanos a su existencia y al pacífico desarrollo de sus vidas, no por mero sentimiento de piedad, sino por reconocer obligaciones éticas respectos de ellos que se derivan de la circunstancia de participar conjuntamente de un todo vivo.

\footnotetext{
15 Lovelock, James. Homenaje a Gaia. La vida de un científico independiente. Pamplona, 2006.

16 Margulis, Lyon y Sagan, Dorion. Microcosmos. Cuatro mil millones de años de evolución desde nuestros ancestros microbianos. Barcelona. Tusquets, 2008. p 140.

17 Idem. p 170.

18 Capra, Fritjof. La rete della vita. Milano 1997: p. 296.
} 


\section{Sínodo de la Amazonía, Laudato Si y la Ecología Integral}

Es llamativo que una de las críticas más profunda a esa forma de progreso occidental, venga de una de las instituciones pilares de la modernidad. Sin duda la iglesia católica fue fundamental en la consolidación de los estados-nación europeos y en los proceso de colonización de América, que luego derivaron en la imposición del sistema capitalista a nivel global. Sin embargo actualmente parece encontrarse en un proceso de profunda autocrítica:

En la Asamblea Especial del Sínodo de los Obispos para la región Panamazónica, el 27 de Octubre de $2019^{19}$ expresaron su preocupación sobre la dramática situación de destrucción que afecta a la Amazonía. Esto que significa la desaparición del territorio y de sus habitantes, especialmente de los pueblos indígenas. La Amazonía desempeña un papel central como amortiguador del cambio climático y proporciona fundamentales sistemas de soporte vitales relacionados con el aire, el agua, los suelos, los bosques y la biomasa. ${ }^{20}$ Se trata de un extenso territorio con una población estimada en 33.600.000 habitantes, de los cuales entre 2 y 2,5 millones son indígenas. Este espacio, conformado por la cuenca del río Amazonas y todos sus tributarios, se extiende por 9 países: Bolivia, Perú, Ecuador, Colombia, Venezuela, Brasil, Guyana, Surinam y Guayana Francesa.

La región amazónica es esencial para la distribución de las lluvias en las regiones de América del Sur y contribuye a los grandes movimientos de aire alrededor del planeta. Pero en la actualidad es la segunda área más vulnerable del mundo con relación al cambio climático por la acción directa del hombre. Una de las causas principales de la destrucción en la Amazonía

\footnotetext{
19 http://www.sinodoamazonico.va/content/sinodoamazonico/es/documentos/documentofinal-de-la-asamblea-especial-del-sinodo-de-los-obispo.html

20 http://www.sinodoamazonico.va/content/sinodoamazonico/es/documentos/documentofinal-de-la-asamblea-especial-del-sinodo-de-los-obispo.html (Capítulo I, parr. 10 y 11)
} 
es el extractivismo predatorio que responde a la lógica de la avaricia, propia del paradigma tecnocrático dominante ( $L S 101$ ).

La crisis socio-ambiental que amenaza la vida, se refleja en la apropiación y privatización de bienes de la naturaleza, como la misma agua; las concesiones madereras legales y el ingreso de madereras ilegales; la caza y la pesca predatorias; los mega-proyectos no sostenibles (hidroeléctricos, concesiones forestales, talas masivas, monocultivos, carreteras, hidrovías, ferrocarriles y proyectos mineros y petroleros); la contaminación ocasionada por la industria extractiva y los basureros de las ciudades y, sobre todo, el cambio climático. La comunidad científica, por su parte, advierte de los riesgos de la deforestación, que hasta la fecha se acerca a casi el 17\% del bosque amazónico, y amenaza la supervivencia de todo el ecosistema, pone en peligro la biodiversidad y cambia el ciclo vital del agua para la supervivencia del bosque tropical.

En el capítulo IV de Laudato Si Francisco propone la ecología integral, conectando la ecología con la justicia social. «Un verdadero planteo ecológico se convierte siempre en un planteo social, que debe integrar la justicia en las discusiones sobre el ambiente, para escuchar tanto el clamor de la tierra como el clamor de los pobres» ( $L S$ 49) La ecología integral conecta el ejercicio del cuidado de la naturaleza con la justicia por los más empobrecidos y desfavorecidos de la tierra. ${ }^{21}$

"Cuando se habla de "medio ambiente", se indica particularmente una relación, la que existe entre la naturaleza y la sociedad que la habita. Esto nos impide entender la naturaleza como algo separado de nosotros o como un mero marco de nuestra vida. Estamos incluidos en ella, somos parte de ella y estamos interpenetrados. Las razones por las cuales un lugar se contamina exigen un análisis del funcionamiento de la sociedad, de su economía, de su comportamiento, de sus maneras de entender la realidad. Dada la magnitud de los cambios,

210 cit; Cap IV, parr 66. 
ya no es posible encontrar una respuesta especifica e independiente para cada parte del problema. Es fundamental buscar soluciones integrales que consideren las interacciones de los sistemas naturales entre sí y con los sistemas sociales. No bay dos crisis separadas, una ambiental y otra social, sino una sola y compleja crisis socio-ambiental. Las líneas para la solución requieren una aproximación integral para combatir la pobreza, para devolver la dignidad a los excluidos y simultáneamente para cuidar la naturaleza." (LS 139)

\section{Neoconstitucionalismo nuestroamericano: Derecho a la Naturaleza y Sumak Kawasay}

$\mathrm{Y}$ es de los pueblos originarios de la amazonía que se ha retomando el ideal de convivencia armoniosa con la naturaleza (sumak kawsay), siglos de colonialismo primero y etnocentrismo blanco republicano después no pudieron borrar de la cultura de los pueblos originarios del culto a la Tierra. No es casual que esta respuesta no haya venido de la mano de elaboraciones científicas, sino como manifestación del saber de la cultura ancestral de convivencia con la naturaleza (el ochenta por ciento de biodiversidad en nuestra región se encuentra en territorio indígena) ${ }^{22}$. Estas culturas que incluso desde su ritualidad, saben respetar los ciclos vitales de la tierra, y cada primero de agosto le dan de comer y beber. El progreso occidental por el contrario ha desarrollado técnicas para ahogarla en cemento, depredarla y envenenarla con cianuro (utilizado en megaproyectos de minería a cielo abierto) o glifosato (herbicida utilizado para el monocultivo de soja transgénica).

Ya ha sido nuestro continente el emergente de procesos constituyentes que dieron respuesta a las crisis que se pone manifiesto en nuestro sistema. En 1917 de la revolución mexicana, parió la Constitución de Queretaro, emergiendo los

22 Pacari, Nina; "Naturaleza y territorio desde la mirada de los pueblos indígenas" en Acosta, Alberto y Martinez, Esperanza (Derechos de la Naturaleza). Quito, Abya Ayala, 2009. 
llamados derechos sociales, que intentaron paliar las enormes desigualdades que sembraba el capitalismo. Del mismo modo, de los levantamientos indígena-campesinos de este siglo, nacieron procesos constituyentes en Bolivia y Ecuador, que plantearon el reconocimiento de derechos a la Naturaleza, vislumbrando el colapso civilizatorio que significó la imposición del capitalismo global, en su versión más voraz, de la mano del totalitarismo financiero y la sociedad de consumo.

El preámbulo de la Constitución de la República del Ecuador dice: "Celebrando a la naturaleza, la Pachamama, de la que somos parte y que es vital para nuestra existencia", y después señala que: "Decidimos construir: Una nueva forma de convivencia ciudadana, en diversidad y armonía con la naturaleza, para alcanzar el buen vivir, el sumak kawsay." El capítulo VII de la Constitución de Montecristi se refiere a Derechos de la naturaleza o sea que desde el título la reconoce como titular de derechos. En consonancia con esta posición, el artículo $71^{\circ}$ dispone: "La naturaleza o Pachamama, donde se reproduce y realiza la vida, tiene derecho a que se respete integralmente su existencia y el mantenimiento y regeneración de sus ciclos vitales, estructura, funciones, procesos evolutivos. Toda persona, comunidad, pueblo o nacionalidad podrá exigir a la autoridad pública el cumplimiento de los derechos de la naturaleza. Para aplicar e interpretar estos derechos observer en los principios establecidos en la Constitución, en lo que proceda. El Estado incentivará a las personas naturales y jurídicas, y a los colectivos, para que protejan la naturaleza, promoverá el respeto a todos los elementos que forman un ecosistema."

El preámbulo de la Constitución Política del Estado Plurinacional de Bolivia dice: "Cumpliendo con el mandato de nuestros pueblos, con la fortaleza de nuestra Pachamama y gracias a Dios, refundamos Bolivia. El artículo $33^{\circ}$ prescribe: Las personas tienen derecho a un medio ambiente saludable, protegido y equilibrado. El ejercicio de este derecho debe permitir a los individuos y colectividades de las presentes y futuras 
generaciones, además de otros seres vivos, desarrollarse de manera normal y permanente. El artículo $34^{\circ}$ complementa el anterior disponiendo: Cualquier persona, a título individual o en representación de una colectividad, está facultada para ejercer las acciones legales en defensa del medio ambiente, sin perjuicio de la obligación de las instituciones públicas de actuar de oficio frente a los atentados contra el medio ambiente."

Si bien el texto de la Constitución boliviana enuncia la cuestión ambiental como un derecho de carácter social y económico, encabezando el capítulo referido a tales derechos, y con ello parece inclinarse por la tendencia ambientalista prevalente de considerarlo un derecho de los humanos, en su texto no deja de referirse a otros seres vivos, lo que importa reconocerles derechos. En cuanto a sus consecuencias prácticas, habilita a cualquier persona, de modo amplio, a ejercer las acciones judiciales de protección, sin el requisito de que se trate de un damnificado, que es la consecuencia inevitable del reconocimiento de personería a la propia naturaleza, conforme a la invocación de la Pachamama entendida en su dimensión cultural de Madre Tierra. Es clarísimo que en ambas constituciones la Tierra asume la condición de sujetos de derechos, en forma expresa en la ecuatoriana y tácita en la boliviana, pero con iguales efectos en ambas: cualquiera puede reclamar por sus derechos, sin que se requiera que sea afectado personalmente, supuesto que sería primario si se la considerase un derecho exclusivo de los humanos.

De este modo el constitucionalismo andino dio el gran salto del ambientalismo a la ecología profunda, es decir, a un verdadero ecologismo constitucional. La invocación de la Pachamama va acompañada de la exigencia de su respeto, lo que Alberto Filippi denominó Ecosofía Política ${ }^{23}$ que se traduce en la regla básica ética del sumak kawsay, que es una expresión quechua que significa buen vivir o pleno vivir, y que se distingue $y$

23 FILIPPI, Alberto, Constituciones, dictaduras y democracias Los derechos y su configuración política, Infojus, Ciudad Autonoma de Buenos Aires, 2015; p 543 
opone a la concepción Occidental del progreso acumulativo e indefinido del "vivir mejor". Una reconfiguración cultural y política de los derechos, a diferencia de la tradición filosófico y jurídico-político que ha denominado occidente durante siglos, se empieza a reivindicar una ética de la naturaleza. ${ }^{24}$

No se trata del tradicional bien común reducido o limitado a los humanos, sino del bien de todo lo viviente, el respeto jurídico a la biodiversidad, incluyendo por supuesto a los humanos, entre los que exige complementariedad y equilibrio, no siendo alcanzable individualmente. Una intercomunicación entre todo el cosmos, donde no hay excluyentes ni excluidos, y donde podamos forjar un proyecto de vida plena para todos. ${ }^{25}$

Como bien hace memoria el filósofo guatemalteco Francisco Márquez, el "concepto de Sumak Kawsay o Buen Vivir, tiene su punto de partida en nuestra América. Tiene su origen en una fusión de culturas que recoge las sabidurías milenarias de Abya Yala para aportar sus valores al diálogo e integración de las culturas del mundo en la formación de un nuevo paradigma universal que contribuya a la construcción de un nuevo mundo. Plantea su visión sustentada en la convivencia del ser bumano en diversidad y armonía con la naturaleza y lo bace a partir del reconocimiento de los diversos valores culturales existentes en cada región y en el mundo".

"El Sumak Kawsay es la confluencia de las diversas culturas ancestrales, de donde surge la sabiduría de los pueblos que están decididos a construir una forma de vida ciudadana, en diversidad y armonía con la naturaleza, en respeto a la dignidad de todas las personas y las colectividades. El Sumak Kawsay provoca un vuelco frente a la concepción ilustrada europeizante, basada en el bienestar burgués, individualista y antropocéntrico, que en nuestro continente rige todavía a muchos

\footnotetext{
24 Filippi 0,cit; 545

25 http://www.sinodoamazonico.va/content/sinodoamazonico/es/documentos/ documento-final-de-la-asamblea-especial-del-sinodo-de-los-obispo.html ; Cap 1, 9.
} 
Estados-nación modernos". "Con una visión renovada estamos regresando a nuestros orígenes para seguir el camino después de habernos extraviado por sendas equivocadas que absolutizaban y favorecían el análisis sobre la síntesis, la racionalidad sobre la intuición, la ciencia sobre la sabiduría, la competición sobre la cooperación y así sucesivamente hasta el punto de llevarnos a un desequilibrio tan alarmante que ha desembocado en una crisis de dimensiones sociales, ecológicas, morales y espirituales de tal magnitud que están poniendo en peligro la vida en el planeta". "Vemos abora que los cambios están surgiendo desde nuestra propia Abya Yala, con la idea clara del derecho que tienen los pueblos a configurar el mundo de acuerdo con su propia conciencia y cultura. Con ello se está abriendo paso bacia la recuperación de nuestras raíces milenarias, en respeto a los tiempos históricos de las culturas y a la conciencia que tienen de no seguir sometidas a los designios de la economía sino a ritmos humanos en armonía con la naturaleza"26

Siendo una regla de convivencia que en modo alguno niega la utilización de la naturaleza y ni siquiera de la técnica, sino que exige respeto a todo lo humano y no humano. Tiene implicancias de todo orden en el plano político y económico y, naturalmente, enfrenta decididamente al suicida festival de la sociedad de consumo y al mal llamado "neoliberalismo", que podríamos rebautizar neocolonialismo o totalitarismo financiero.

\section{Hacia una Constitución de la Tierra}

En ese sentido también se inscribe la iniciativa de Luigi Ferrajoli de la "Constitución de la tierra" 27 , una propuesta política que intenta dar respuesta a problemas globales de la humanidad

26 Francisco Márquez, "Sumak Kawsay: valores y Buen Vivir en las culturas ancestrales”, en Cuadernos Americanos N 146, México, pp. 107/108.

27 La Escuela "Tierra Constituyente" se inauguró el 21 de Febrero de 2020 en la Biblioteca Vallicelliana de Roma (piazza della Chiesa Nuova 18), cuya institución, con el atractivo “ ¿Por qué una Constitución de la Tierra?", se anunció en el Manifiesto del 27 de diciembre 2020. 
que amenazan su propia supervivencia. En una entrevista otorgada al diario "El País" de España, el filósofo y jurista italiano dijo: "Son problemas globales que no forman parte de la agenda politica de los Gobiernos nacionales y de cuya solución, sólo posible a escala global, depende la supervivencia de la humanidad: el salvamento del planeta del cambio climático, los peligros de conflictos nucleares, el crecimiento de la pobreza y la muerte de millones de personas cada año por la falta de alimentación básica y de fármacos esenciales, el drama de los centenares de miles de migrantes y, ahora, la tragedia de esta pandemia."28

Ferrajoli sostiene que una constitución es legítima y democrática no porque sea querida por todos, sino porque garantiza a todos. ${ }^{29}$ Para el jurista italiano ya disponemos de un embrión de una constitución global, compuesto por la Carta de las Naciones Unidas y las numerosas otras cartas, declaraciones, convenciones y pactos internacionales sobre derechos humanos, y que en términos de legislación el paradigma constitucional ya se ha incorporado al ordenamiento internacional. En su escuela propone un nuevo movimiento de opinión y lucha política que debe ser activado por la movilización de millones de jóvenes en defensa de la Tierra. Y cuya primera asamblea tuvo lugar en la Biblioteca Vallicelliana de Roma, el 21 de febrero de este año. Un constitucionalismo planetario que colme las lagunas que dejan las constituciones nacionales, mediante la creación, no tanto de instituciones de gobierno que deben seguir confiadas a los Estados, sino de funciones e instituciones globales de garantía de los derechos humanos.

"El dilema actual es mucho más dramático del planteado entonces. De becho, hay dos diferencias profundas entre la sociedad natural del bomo bomini lupus teorizada por Hobbes y el estado de naturaleza en que se encuentran los 196 estados

28 Nota:https://elpais.com/ideas/2020-03-27/luigi-ferrajoli-filosofo-los-paises-de-la-ue-vancada-uno-por-su-lado-defendiendo-una-soberania-insensata.html (vista el 8 de Julio de 2020)

29 Ferrajoli, Luigi, “¿Por qué una Constitución de la Tierra?”, del día 27 de diciembre de 2019, p 2. 
soberanos y los grandes poderes económicos y financieros mundiales, dotados a la vez de soberanía absoluta. La primera, es que la sociedad salvaje actual de poderes globales es una sociedad poblada no por lobos naturales, sino por lobos artificiales, los estados y los mercados, sustancialmente liberados del control de sus creadores y dotados de una fuerza destructiva incomparablemente mayor que cualquier armamento del pasado. La segunda es que, a diferencia de todas las otras catástrofes del pasado -las guerras mundiales, los horrores de los totalitarismos-, la catástrofe ecológica y nuclear es en gran medida irreversible, y tal vez no haya tiempo de formular nuevos "nunca más": en efecto, pues existe el peligro de adquirir conciencia de la necesidad de un nuevo pacto cuando sea demasiado tarde."30

Sin embargo hoy no son los Estados los que garantizan la competencia entre las empresas, sino por el contrario, las grandes empresas transnacionales las que ponen a competir a los Estados, privilegiando a aquellos en los que son menores las garantías laborales y menor o inexistente la tutela del medioambiente. Por esta razón, plantea una la alternativa radical que desarrolle "un proceso constituyente de carácter supranacional, primero europeo y luego mundial, es decir, la construcción de una esfera pública planetaria capaz de establecer límites a la soberanía salvaje de los mercados y de los estados más poderosos, para garantizar los derechos y los bienes vitales de todos, o no sólo estarán en peligro nuestras democracias, sino también la paz y la habitabilidad del planeta."31

Ferrajoli, propone la recuperación del derecho romano de la figura del demanio, es decir, la sustracción de los bienes comunes al mercado a través de su calificación de bienes de dominio público. Un futuro demanio planetario del cual deberían formar parte el agua potable, los glaciares, los mares, las costas marinas y la selva amazónica, víctima cada año de incendios

\footnotetext{
30 Ferrajoli, Luigi, “¡Por qué una Constitución de la Tierra?",del día 27 de diciembre de 2019, p 4

31 Ob. cit, p 3
} 
criminales. ${ }^{32}$ En nuestra región se ha esbozado una nueva fase del constitucionalismo que tiene como objetivo reconocer, junto con los derechos fundamentales, los bienes fundamentales, en cuanto vitales o comunes como el agua, el aire, el suelo y los bosques, sustrayéndoles al mercado y a la disponibilidad de la política. Estipulando para ellos el estatus inderogable de bienes constitucionales, a fin de preservarlos y hacerlos accesibles a todos.

\section{Conclusiones}

Centrar la cuestión únicamente sobre el virus y su vacuna omitiría la visión biológica total, ocultando la fuente de producción del virus, que seguirá fabricando otros con la misma velocidad que se destruye el ecosistema, causando nuevas infecciones y muertes. Para combatir los virus surgen nuevas "técnicas" y nuevas vacunas, que son producidas con aportes de investigación pública, y son aprovechados por corporaciones transnacionales que las perfeccionan y patentan, limitando su difusión en los países empobrecidos. El autor resalta como en India se registran cien mil muertes por neumonía infantil por año, mientras la corporación que patentó la vacuna recauda 5.000 millones de dólares anuales. ${ }^{33}$

Deberíamos discutir cómo ponerle un freno a corporaciones transnacionales que destruyen el equilibrio de la Pachamama o Gaia, deforestando bosques, envenenando suelos, depredando especias y destruyendo montañas, y que luego patentan las vacunas a los virus que este sistema genera. La forma de impedir este devenir catastrófico que puede incluir nuestra propia extinción quizá sea tutelar, a la hasta ahora indefensa, naturaleza. Poniéndole límites a la voracidad insaciable del capitalismo global, no ya por un sentimiento de piedad o conciencia de las generaciones futuras, sino recuperando un instinto animal

32 Ob. Cit, p 13.

33 Zaffaroni; Ob. Cit .p 2 
de supervivencia que nos haga respetar las reglas éticas de la naturaleza, respetar sus equilibrios y ciclos vitales, para vivir en armonía, colaboración y complementariedad con ella.

Como dijo Ferrajoli: "a diferencia de todas las otras catástrofes del pasado -las guerras mundiales, los horrores de los totalitarismos-, la catástrofe ecológica y nuclear es en gran medida irreversible, y tal vez no haya tiempo de formular nuevos "nunca más": en efecto, pues existe el peligro de adquirir conciencia de la necesidad de un nuevo pacto cuando sea demasiado tarde." 34

Establecer de esta forma a la naturaleza como nuevo sujeto de derecho y en ese proceso reconocer reglas éticas inviolables que limiten al dominus torturador del conocimiento occidental. $\mathrm{Y}$ en paralelo sustituir el concepto de progreso acumulativo e indefinido del "vivir mejor", basado en el consumo y la depredación, por el buen vivir (Sumak Kawsay) que supone una vida armoniosa entre lo humano y lo no humano. Esta reflexión debe servirnos para cuestionarnos sobre la metáfora de guerra al virus, y preguntarnos si el enemigo es el virus o quién lo produce. Así como el Ángel de la Historia, según Walter Benjamin mira hacia atrás (al pasado) como el "Angelus Novus" del cuadro de Klee. El neoconstitucionalismo nuestroamericano mira a sus ancestros y en su proceso descolonización del poder y del saber da señales al mundo de un mejor destino para la humanidad.

34 Ferrajoli, Luigi, “¿Por qué una Constitución de la Tierra?”, del día 27 de diciembre de 2019, p 4. 